\title{
Effect of Coexisting Natural Organic Matters (NOM) on the Rejection of Endocrine Disrupting Chemicals (EDCs) by A Low Pressure Reverse Osmosis (LPRO) Membrane
}

Received in revised form 15 March 2005, accepted 15 March 2005

\author{
Hiroaki Ozaki ${ }^{1}$, Norihito Ikejima ${ }^{2} \&$ Saburo Matsui ${ }^{3}$
}

${ }^{1}$ Department of Civil Engineering, Osaka Sangyo University, 3-1-1 Nakagaito, Daitoshi, 574-8530 Osaka, Japan

${ }^{2 \& 3}$ Graduate School of Global Environmental Studies, Kyoto University, Japan

\begin{abstract}
The coexisting natural organic matters (NOM) in the water environment are expected to influence rejections of endocrine disrupting chemicals (EDCs) in membrane filtration. However, such influences and rejection mechanisms are not well understood. This paper aims to elucidate on the rejection of three representative EDCs: Bisphenol A (BPA), 17ß-estradiol (E2) and 4-Nonylphenol (NP) by a LPRO membrane (UTC-60) with and without three representative NOM: humic acid (HA), fulvic acid (FA) and effluent organic matters (EfOM) in solutions by laboratory experiments. The EDCs rejections were enhanced with increasing solution $\mathrm{pH}$ and negative membrane zeta potential as a result of decreased membrane pore size. Adsorption of the EDCs on membrane surface and size exclusion were the most likely rejection mechanisms in absence of the NOM. Coexistence of the NOM in solutions, in general, enhanced the EDCs rejections. However, no specific trends in rejection were observed possibly due to diffusion of the adsorbed NOM and EDCs molecules through the membrane pores, physicochemical properties of the EDCs and several types of NOM molecules present in EfOM. The EDCs adsorption on NOM molecules and their adsorption on the membrane surface and/or retention by size exclusion were the most likely rejection mechanisms.
\end{abstract}

Keywords : Coexisting natural organic matters (NOM), endocrine disrupting chemicals (EDCs), low pressure reverse osmosis (LPRO), membrane zeta potential, rejection

\subsection{INTRODUCTION}

Increasing urbanization and industrial activities have led to severe pollution of surface and subsurface water resources by several hazardous micropollutants such as dioxins and endocrine disrupting chemicals (EDCs). Reverse osmosis (RO) membrane filtration is an effective technology in removing organic contaminants with low molecular weight at low concentration levels from water and wastewater. However, its use is limited due to the requirement of extensive pretreatment, in addition to high operational and maintenance costs.

* Correspondence to: Hiroaki Ozaki (tel: +81-72-875-3001 (ext. 3718), fax: +81-72-875-5044, e-mail: ozaki@ce.osaka-sandai.ac.jp) 
Low pressure reverse osmosis (LPRO) membrane filtration is emerging as an alternative to the conventional $\mathrm{RO}$ technique in removing wide ranges of organics in contaminated water and wastewater due to its low operating pressure (0.2-0.9 MPa). Several investigations have been devoted to illuminate on rejection behaviors of various organic contaminants by LPRO membranes. The rejections are found to depend on the properties of both contaminants and membrane materials. Ozaki and $\mathrm{Li}$ [1] demonstrated rejection dependency by LPRO membrane on solution $\mathrm{pH}$, and molecular weight and dissociation constant $(\mathrm{pKa})$ of organics. Molecular size and weight were highly significant while $\mathrm{pH}$ effect was not in case of undissociated organics. Rejections of dissociated organics were inversely correlated with $\mathrm{pKa}$ values. Braghetta et al. [2] studied influence of $\mathrm{pH}$ and ionic strength on nanofiltration of natural organic matters (NOM). Thanuttamavong et al. [3] compared rejections of NOM and inorganic salts in ultra low pressure nanofiltration. Ranatamskul et al. [4] introduced a concept of ion partitioning at membrane-solution interface for rejection of chlorides and nitrates in nanofiltration. Ozaki et al. [5] discussed the role of membrane zeta potential on rejection of ionic and dissociated organics by LPRO membranes.

Most of the studies done so far on the rejection characteristics of EDCs by LPRO membranes focused on the cases without coexisting NOM in solutions while coexistence of several natural organic substances are found in actual water and wastewater treatment cases. The important fact is that the influences of coexisting NOM on the EDCs rejections by LPRO membranes and the rejection mechanisms have not been well understood. This paper aims to elucidate on the influence of coexisting NOM on the rejections of EDCs by UTC-60 with laboratory experiments and propose possible rejection mechanisms for the EDCS. The three representative EDCs and NOM employed in the experiments were Bisphenol A (BPA), 17ß-estradiol (E2) and 4-Nonylphenol (NP); and humic acid (HA), fulvic acid (FA) and effluent organic matters (EfOM), which was the effluent from a secondary sewage treatment plant in Osaka, respectively.

\subsection{EXPERIMENTAL}

\subsection{Materials}

UTC-60, a commercial LPRO membrane in flat-sheet form $\left(180 \times 46 \mathrm{~mm}\right.$ sizes and $60 \mathrm{~cm}^{2}$ effective surface area) manufactured by TORAY Industry Inc and a cross-flow module C-10T $(210 \times 110 \times 82 \mathrm{~mm}$ sizes $)$ manufactured by Nitto Denko Corporation were employed in the continuous laboratory experiments in this investigation. The $\mathrm{pH}$ of the feed solutions was adjusted using $\mathrm{HCl}$ and $\mathrm{NaOH}$ solutions with pH controller. Bisphenol A (BPA), 17 $\beta$-estradiol (E2) and 4-Nonylphenol (NP) were three representative EDCs in the experiments obtained from Wako Pure Chemicals. Humic acid (HA) obtained from Aldrich Ltd. and fulvic acid (FA) extracted from HA[6] were used as coexisting natural organic matters (NOM) with the EDCs. Effluent from a secondary sewage treatment plant (hereinafter called "effluent organic matters" and denoted by "EfOM") in Osaka, Japan, was used in the experiments to examine the EDCs rejection characteristics by the membrane.

\subsection{Methods}

The flat sheet UTC-60 membrane was stored in deionized water at $5^{\circ} \mathrm{C}$ before its use in the experiments. The membrane was mounted on the cross-flow module and continuous laboratory experiments were carried out at $25^{\circ} \mathrm{C}$ room temperature with $0.3 \mathrm{MPa}$ operating pressure and $1.2 \ell / \mathrm{min}$. flow rate. Membrane efficiency tests were conducted with $100 \mathrm{mg} / \ell$ sodium chloride 
solution. The initial concentrations of EDCs in the solutions were $1.0 \mathrm{mg} / \ell$. Permeate samples were taken at every 30-minutes interval for flux and concentration measurements for over three hours period. EDCs with small aqueous solubility (for example: NP) were first dissolved in a small amount of methanol before making their solutions in deionized water. Rejections of the EDCs by the membrane were examined in aqueous solutions of the individual EDCs at a solution $\mathrm{pH}$ range from 4 to 10 . Their rejections in presence of HA, FA and EfOM as coexisting NOM were also investigated at neutral solution $\mathrm{pH}$. The percentage rejection by the membrane was calculated using the relation: $\mathrm{R}=\left(1-\mathrm{C} / \mathrm{C}_{0}\right) \times 100$, where $\mathrm{C}$ and $\mathrm{C}_{0}$ are concentrations $(\mathrm{mg} / \ell)$ in feed and permeate solutions, respectively.

Concentrations of the EDCs in their individual solutions in deionized water and mixed with coexisting NOM were measured using fluorescence photometer (FP-6300, JASCO Corporation). The adsorption coefficient of a NOM with an EDC is defined as the amount of the EDC (e.g. mg) adsorbed per kilogram carbon content of the NOM per unit concentration of the EDC in deionized water (e.g. $\mathrm{mg} / \ell$ ). The values were determined in laboratory using fluorescence quenching method discussed elsewhere [7]. Enzyme-linked immunosorbent assay (ELISA) test kits (Japan Environmental Chemicals Ltd.) were employed to measure concentrations of the EDCs mixed with the NOM. HA and FA concentrations were measured with total organic carbon (TOC) analyzer (TOC-500A, Shimadzu). Membrane zeta potential was measured with Zeta-CAD (CAD Instruments Ltd., France) using streaming potential method with $10^{-3} \mathrm{~mol} / \ell \mathrm{NaCl}$ electrolyte [5]. The zeta potential values were calculated using the well-known Helmholz-Smoluchowski formula: $\zeta=1.06 \times 10^{5} \times$ $(1 / \rho) \times(E / P)$, where $\rho:$ specific resistance of solution and $E / P$ : potential difference in operating pressure condition. Molecular weights of organic substances present in HA, FA and EfOM were measured with size-exclusion high performance liquid chromatography (Hitachi, Japan) using both RI and UV (280 nm) detectors. The mobile phase was $10 \mathrm{mM}$ phosphate buffer solution (pH 7.4) with $1.0 \mathrm{~m} \ell / \mathrm{min}$. flow rate. Hitachi GL-W520 column with $35^{\circ} \mathrm{C}$ oven temperature was used in the analysis. A standard curve between molecular weight and retention time (RT) was obtained by injecting Polyethylene Glycol standards in size-exclusion chromatography. The weights of molecules in HA, FA and EfOM were determined using retention times from their individual chromatograms and the standard curve.

\subsection{RESULTS AND DISCUSSION}

\subsection{Characteristics of UTC-60 and the EDCs}

UTC-60 is classified as LPRO membrane in nanofiltration (NF) group. It is made of aromatic polyamide material and characterized by carboxyl and amine functional groups. The operating feed pressure for this membrane ranges between 10 and $20 \mathrm{kgf} / \mathrm{cm}^{2}$ while reference rejection value of $0.05 \%$ sodium chloride solution is $55 \%$. The isoelectric point of this membrane with $10^{-3} \mathrm{~mol} / \mathrm{l} \mathrm{NaCl}$ electrolyte was found at $\mathrm{pH} 2.58$. Some physicochemical properties of the three EDCs are shown in Table 1. The values of dissociation coefficient $(\mathrm{pKa})$ and logarithm of octanol-water partition coefficient $\left(\log \mathrm{K}_{\mathrm{OW}}\right)$ in Table 1 were taken from literatures [8-11]. The molecular weights of BPA and $\mathrm{NP}$ are very close while the value for $\mathrm{E} 2$ is the highest among the three. The dissociation coefficient values are similar for all the three. However, $\log \mathrm{K}_{\mathrm{ow}}$ values increased in the order of BPA, E2 and NP, which may have significance on their rejection in membrane filtration. 
Table 1 Physicochemical properties of the EDCs

\begin{tabular}{lcccc}
\hline EDCs Name & Formula & Molecular Wt. & pKa & LogK $_{\text {ow }}$ \\
\hline Bisphenol A (BPA) & $\mathrm{C}_{15} \mathrm{H}_{16} \mathrm{O}_{2}$ & 228.29 & $9.59 \sim 10.56[10]$ & $3.40[10]$ \\
17ß-estradiol (E2) & $\mathrm{C}_{18} \mathrm{H}_{24} \mathrm{O}_{2}$ & 272.38 & $10.40[8]$ & $4.01[8]$ \\
4-Nonylphenol (NP) & $\mathrm{C}_{15} \mathrm{H}_{24} \mathrm{O}$ & 220.35 & $10.30[11]$ & $5.76[9]$ \\
\hline
\end{tabular}

\subsection{Effects of Solution Chemistry and EDCs Properties on Rejection}

Rejections of E2, BPA and NP solutions in deionized water $(1.0 \mathrm{mg} / \mathrm{l})$ by UTC-60 in the pH range 4 to 10 are illustrated in Figure 1. NP and BPA rejections were the highest and the lowest, respectively, among the three EDCs. NP and E2 rejections slightly decreased with increasing solution $\mathrm{pH}$ in the $\mathrm{pH}$ range 4 to 7 while BPA rejection increased. However, the rejections of all the three EDCs increased with increasing solution $\mathrm{pH}$ in the $\mathrm{pH}$ range 7 to 10 and reached about $90 \%$ at $\mathrm{pH} 10$. The increase in EDCs rejections with solution $\mathrm{pH}$ in these experiments is consistent with the results of earlier investigations [1,5,12]. Childress and Elimelch [13] mentioned the influence of solution $\mathrm{pH}$ on membrane surface charge characteristics due to functional groups that protonate and deprotonate over wide $\mathrm{pH}$ range. It is argued that ionization of organic compounds increases with solution $\mathrm{pH}$ resulting in repulsion between negatively charged membrane surface and the organics. Borretzen and Salbu [14] mentioned that ionization of hydrophobic organic compounds in aqueous solutions is $\mathrm{pH}$ dependent. The three EDCs being relatively hydrophobic, their increased rejections with increasing solution $\mathrm{pH}$ can be regarded as the result of increased ionization and electrostatic repulsive force between the membrane surface and the EDCs molecules/ions. Relatively bigger dissociation

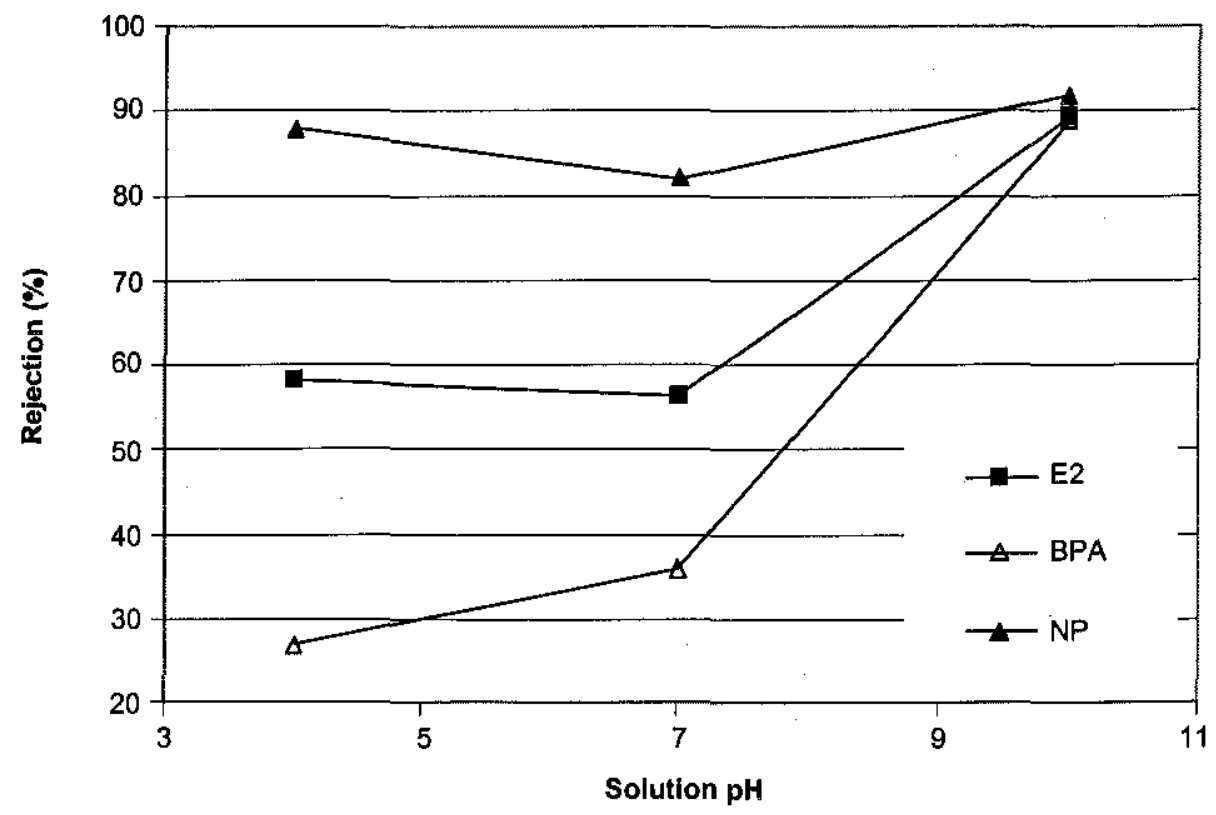

Figure 1 Effect of solution pH on rejections of Bisphenol A (BPA), 17b-estradiol (E2) and 4Nonylphenol (NP) by UTC-60 
coefficient ( $\mathrm{pKa}$ ) values of the EDCs (Table 1) may have been responsible for less than $90 \%$ of the EDCs[1].

The big differences in the EDCs rejections below $\mathrm{pH} 10$ may be mainly attributed to their octanolwater partition coefficient $\left(\mathrm{K}_{\mathrm{ow}}\right)$ values (Table 1). The EDCs with bigger $\log \mathrm{K}_{\mathrm{ow}}$ values showed higher rejections by UTC-60. $\mathrm{K}_{\text {ow }}$ values can be taken as a measure of hydrophobicity of organic compounds $[15,16]$. Hydrophobic organic compounds with $\log \mathrm{K}_{\mathrm{ow}}$ values bigger than 5 strongly partition to octanol phase [9]. The EDCs rejection characteristics observed in Figure 1 may be attributed to hydrophobic interactions between the EDCs molecules and membrane polymeric matrix [8] and partition to octanol phase, because the rejections increased with increasing $\operatorname{LogK}_{\text {ow }}$ values of the EDCs (i.e. BPA, E2 and NP).

Childress and Elimelech [13] mentioned the importance of size exclusion of uncharged solute molecules on their rejection by loose nanofiltration membranes. Molecular weight and size are two important parameters influencing rejection of organics in RO membrane filtration $[1,17]$. The rejection characteristics shown in Figure 1 and the EDCs properties (Table 1) indicated less significance of molecular weight on the rejections. Molecular size rather than weight is described as the dominant single factor in rejection [17]. Following these reasoning, molecular size configurations of the EDCs could have significantly influenced their rejection characteristics in Figure 1.

\subsection{Change in Membrane Zeta Potential with Solution pH}

Zeta potentials of UTC-60, UTC-70U and ES-20 were measured as function of solution pH with $10^{-3} \mathrm{~mol} / \mathrm{l} \mathrm{NaCl}$ electrolyte and the results are shown in Figure 2. Although UTC-60 is the focus of this article, the zeta potential curves for the other two membranes are presented in Figure 2 just for comparison. Zeta potential reflects the state of electric charges on membrane surface. Figure 2 indicates great significance of solution $\mathrm{pH}$ on membrane zeta potential values. The values were positive at strongly acidic conditions, which gradually decreased with increasing solution $\mathrm{pH}$. Zero zeta potential values were obtained at some particular $\mathrm{pH}$ values, which are known as isoelectritic points. The isoelectritic point for UTC- 60 was found at $\mathrm{pH} 2.58$ in these experiments. The negative values of the membrane zeta potential increased with further increasing solution $\mathrm{pH}$ (Figure 2). Such a nature of membrane zeta potential curves is described as the indication of amphoteric surface [13]. The changes in membrane zeta potential from positive to negative values with increasing solution $\mathrm{pH}$ were almost linear.

The variation of membrane zeta potential as a function of solution pH (Figure 2) is consistent with the results of earlier investigations $[5,13,18]$. The lower isoelectritic point for UTC-60 among the three membranes (Figure 2) indicated negative surface charges even at strongly acidic conditions. Childress and Elimelech [18] found NF membranes were more negatively charged than RO membranes in the same testing conditions. The lower isoelectric point for UTC-60 may be attributed to ionizable carboxyl and amine functional groups of the membrane. It is speculated that not only negativity or positivity of membrane zeta potential, but its absolute value can have significant influence on rejections of low-molecular weight organics. Therefore, membrane zeta potential has become a very important parameter to understand rejection characteristics of organic micropollutants in membrane filtration.

Childress and Elimelech $[13,18]$ shed light on several factors influencing surface charge characteristics of some membranes. Positive charge on membrane surface is due most likely to pendant amino groups while negative charge development is attributed to carboxyl groups of aromatic ring. Adsorption of anions such as $\mathrm{Cl}^{-}$and $\mathrm{OH}^{-}$from solution, hydrolysis of excess acetic anhydride, and impurities attached to membrane surface are described as reasons for increased negative zeta potential at elevated solution $\mathrm{pH}$. 


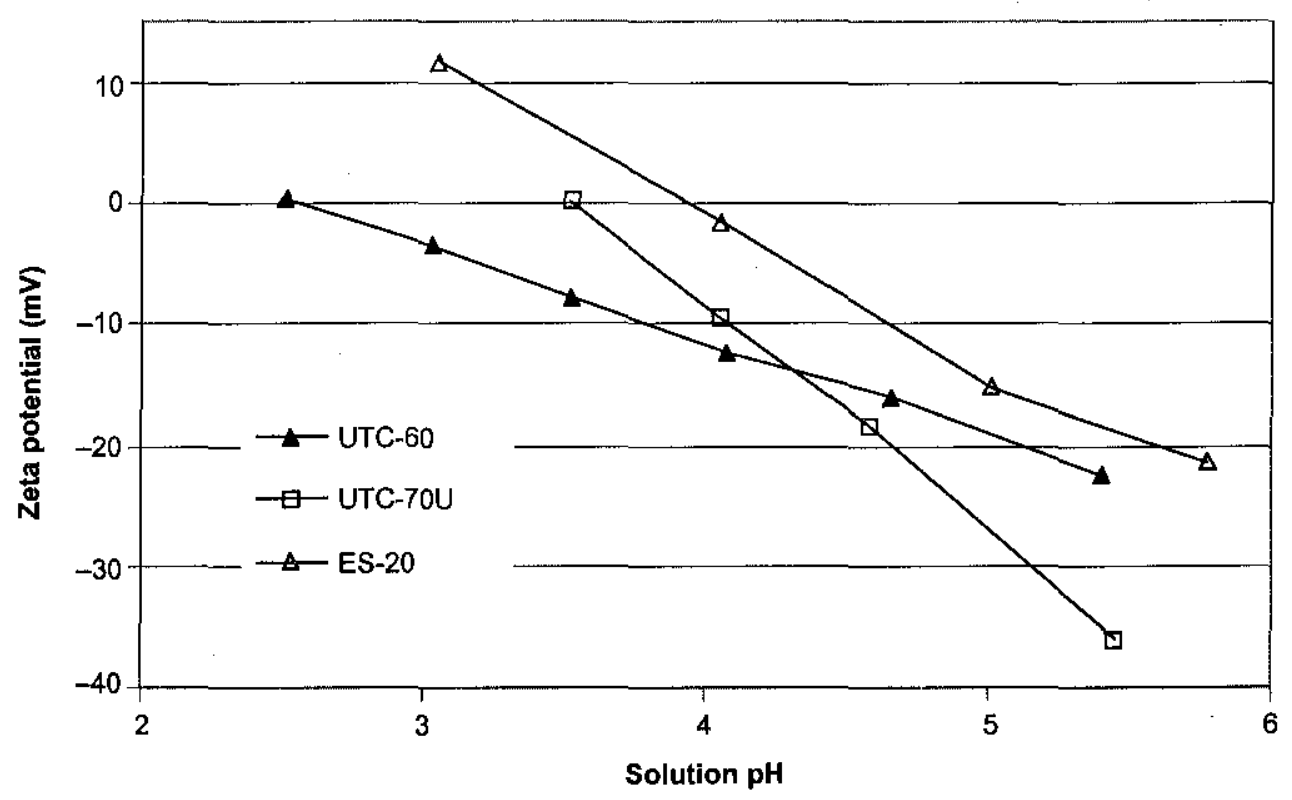

Figure 2 Effect of solution pH on membrane zeta potential (measured with $10^{-3} \mathrm{~mol} / \ell \mathrm{NaCl}$ electrolyte)

\subsection{Influence of Natural Organic Matters}

Rejections of E2, BPA and NP $(1.0 \mathrm{mg} / \ell)$ by UTC-60 in presence of HA $(10.0 \mathrm{mgTOC} / \ell)$, FA $(2.5$ $\mathrm{mgTOC} / \ell$ ) and EfOM were examined at neutral solution $\mathrm{pH}$. Total organic carbon (TOC) removal by the membrane in the EfOM, and HA and FA solutions were also measured with the same solution $\mathrm{pH}$. The results of these laboratory experiments are depicted in Figure 3. Rejections of HA, FA and EfOM in terms of TOC were about 98,78 and $50 \%$, respectively. The results showed the highest rejections of the EDCs with HA. Rejections of $\mathrm{E} 2$ and NP were about 100 and $90 \%$, respectively while BPA rejection was relatively low (about 60\%). The second highest rejections of the EDCs were with FA. However, NP rejection with EfOM was bigger than with FA. It is apparent from the results that the EDCs rejections by UTC- 60 increased in presence of NOM. However, the rejection phenomena did not look to be simple as it is most likely to depend on the characteristics of NOM and the EDCs.

Molecular weights of HA, FA and EFOM, used as coexisting NOM with the EDCs in the laboratory experiments, were measured using high performance size-exclusion liquid chromatography with two types of detectors, and the results are shown in Table 2 . The figures in Table 2 indicated difference between HA and FA molecules in terms of their weights. HA molecules were significantly bigger compared to FA molecules. Yamada et al.[19] also demonstrated that weights of FA molecules obtained from Japanese river waters were smaller than other NOM molecules. Since the rejections of E2 and BPA in presence of HA were bigger than with FA, it is apparent that molecular weight of NOM may have played important role in the EDCs removal. However, the rejections of E2 and BPA with EfOM were significantly smaller than with $\mathrm{HA}$ and $\mathrm{FA}$ even though both big and small molecules existed in EfOM. On the other hand, NP showed entirely different behavior than E2 and BPA in terms of their rejections with NOM. Although HA and EfOM molecules were similar with respect to their weight (Table 2), rejections of E2 and BPA were significantly higher with HA while NP rejection with the two were almost similar (Figure 3). Rejections of the NOM with and without E2 and BPA in solutions were consistent while the scenario was different with NP. The complicated rejection behaviors of the 


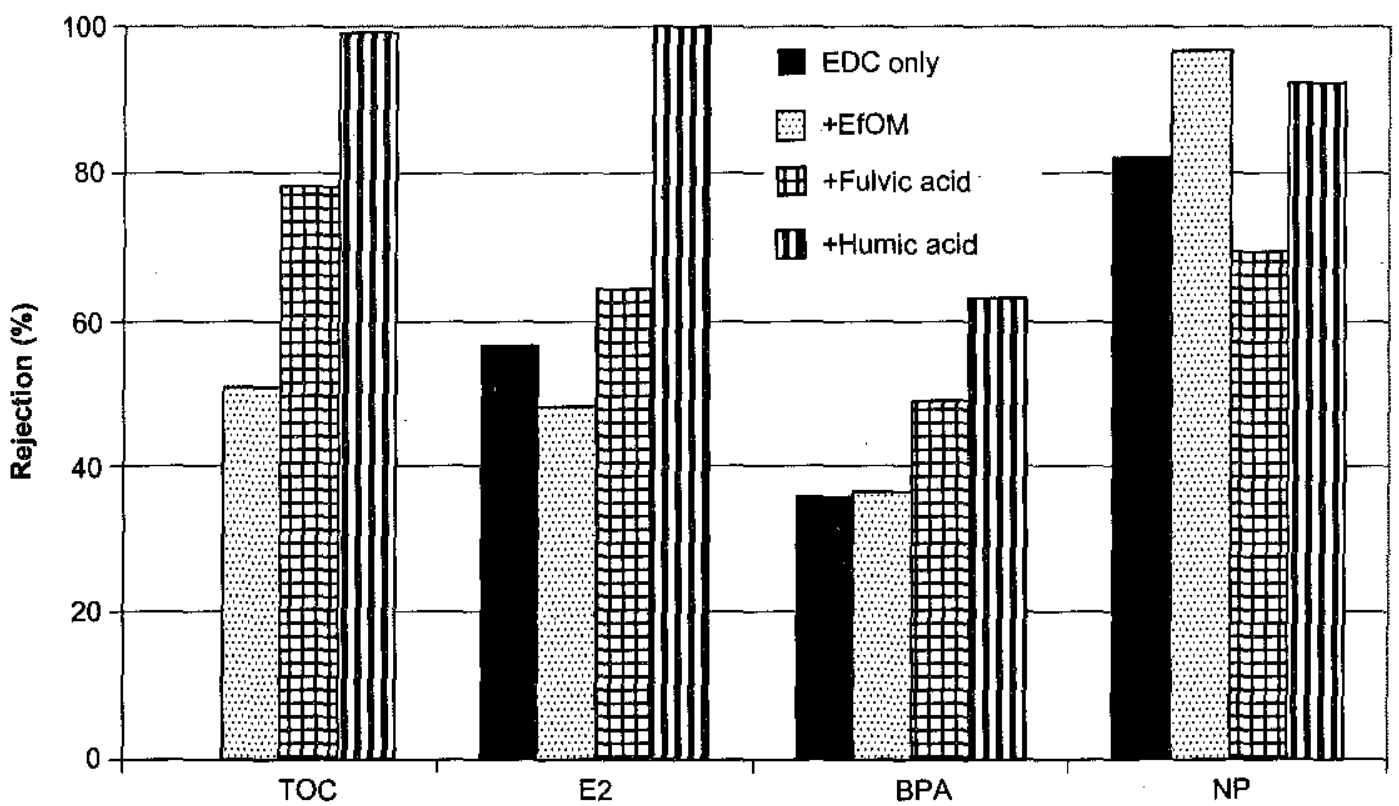

Figure 3 Rejections of BPA, E2 and NP by UTC- 60 in presence and absence of humic acid, fulvic acid and effluent organic matters (EfOM) in solutions at $\mathrm{pH} 7$

Table 2 Molecular weights of NOM molecules from size-exclusion chromatography

\begin{tabular}{cccc}
\hline Detector & & Molecular weight $(\mathrm{g} / \mathbf{m o l})$ & \\
\cline { 2 - 3 } & Humic acid (HA) & Fulvic acid (FA) & Effluent organic matters (EfOM) \\
\hline UV (280 nm) & $1500 \sim 22000$ & $200 \sim 300$ & $2000 \sim 15000$ \\
RI & $2000 \sim 22000$ & $200 \sim 300$ & $5000 \sim 17000$ \\
\hline
\end{tabular}

three representative EDCs with the three NOM in this article may be attributed to unknown interactions among the EDCs and NOM molecules and membrane surface. Nevertheless, the importance of NOM molecular weights on the EDCs rejections by UTC-60 membrane cannot be ignored.

Adsorption of organic micropollutants on membrane surface is one of the important rejection criteria in membrane filtration $[8,13,18]$. It is also well-known that adsorption of organic molecules on NOM molecules is important for the fate of the organics in natural environments $[15,16,20,21]$. Therefore, adsorption of the EDCs on the NOM molecules could have played an important role in addition to their adsorption on membrane surface. Adsorption coefficients $\left(k_{d}\right)$ values for HA and FA used in this investigation with the three EDCs were determined in the laboratory, which are shown in Table 3. The higher rejections of the EDCs with HA compared with FA may be attributed to almost two-fold bigger $k_{d}$ values of HA. Considerable amounts of FA can be found in domestic wastewaters. The smaller rejections of E2 and BPA in EfOM may be due to presence of FA and other low-molecular weight NOM in EfOM. However, BPA rejections were significantly smaller than E2 rejections in spite of similar $k_{d}$ values of HA and FA with the EDCs. Similarly, E2 rejection in presence of HA was the highest although the $k_{d}$ value of HA with NP was the biggest among the three EDCs. 
Table 3 Adsorption coefficient $\left(k_{d}\right)$ of humic and fulvic acids with the EDCs

\begin{tabular}{lccc}
\hline \multirow{2}{*}{$\begin{array}{l}\text { Natural organic } \\
\text { matters (NOM) }\end{array}$} & \multicolumn{3}{c}{$\boldsymbol{k}_{d}$ values $\left(\times 10^{4} \ell / \mathbf{k g}\right.$ carbon content) } \\
\cline { 2 - 4 } & Bisphenol A (BPA) & 17 $\beta$-estradiol (E2) & 4-Nonylphenol (NP) \\
\hline Humic acid & 4.7 & 4.8 & 10.0 \\
Fulvic acid & 2.4 & 2.6 & 5.0 \\
\hline
\end{tabular}

Therefore, it was more likely that $k_{d}$ value only was not a single dominant factor in EDCs rejection with NOM by UTC-60.

Unlike the EDCs rejections by UTC-60 in absence of NOM (Figure 1), their rejections did not increase with $\log \mathrm{K}_{\mathrm{ow}}$ values in presence of the NOM. NP with the biggest $\log \mathrm{K}_{\mathrm{ow}}$ value showed the second biggest rejections with HA while its rejections with FA and EfOM were bigger than for E2. The rejections of BPA, E2 and NP in presence of NOM were not in the order of their $\log \mathrm{K}_{\text {ow }}$ values. The EDCs rejections with EfOM exhibited haphazard, but interesting patterns than with HA and FA (Figure 3). Rejection of organic substances in EfOM in terms of TOC by the membrane without the EDCs in it was only about $50 \%$. However, the rejection of NP with the EfOM increased up to about 95\% while E2 rejection with EfOM was smaller than its rejection without EfOM. The smaller rejections of E2 and BPA with EfOM could possibly be due to smaller NOM molecules present in EfOM, which may not be detected in the size-exclusion chromatography. The E2 and BPA molecules could have been adsorbed on such smaller NOM molecules and passed through the membrane pores. The bigger rejections of NP with EfOM can be explained in the similar basis as with HA since the weights of NOM molecules in EfOM were comparable to that in HA. This explanation is more realistic since EfOM, in general, contains several types of organic molecules. Nevertheless, the rejection scenario observed in Figure 3 may be attributed to the physicochemical properties of the EDCs and varieties of organic matters present in EfOM.

\subsection{EDCs Rejection Mechanisms}

The results presented so far did indicate the significance of solution $\mathrm{pH}$, membrane zeta potential and NOM on rejections of the three EDCs by UTC- 60 membrane. UTC- 60 being relatively loose RO membrane, dissociation characteristics of the EDCs in aqueous solutions can be more important in rejection than their molecular weight [17] although significance of sieving effect due to molecular size configuration cannot be ignored.

Size exclusion, charge exclusion and adsorption are pointed out to be the major criteria for rejections of organics by NF membranes $[8,18]$. Uncharged organic molecules are primarily retained by size exclusion while both size and charge exclusion mechanisms are important in case of ionic species [13]. Since the three EDCs are relatively less ionizable in water phase, size exclusion and adsorption criteria are expected to be dominant in their rejections. Childress and Elimelech[13] argued that membrane pore size decreases with increasing solution $\mathrm{pH}$ due to electrostatic interactions between charged groups. In other words, membrane pore size shrinks with increasing surface electric charge (i.e. membrane zeta potential). This argument is consistent with the results obtained in this investigation since the EDCs rejections increased with increasing solution $\mathrm{pH}$ and membrane zeta potential for UTC-60. Therefore, size exclusion was most likely one important mechanism for the EDCs rejections by UTC-60 in absence of NOM impurities.

Nghiem et al. [8] pointed out size exclusion and adsorption as two major mechanisms for retention of natural hormones by NF membranes. The authors argued that retention of organic molecules by 
NF membranes initially is mainly due to adsorption of the organics on membrane surface, which is most likely driven by hydrophobic or hydrogen bonding while size exclusion mechanism plays major role at the later stage of membrane filtration. The $\log \mathrm{K}_{\text {ow }}$ values of the EDCs (Table 1) and their rejections in absence of NOM (Figure 1) are consistent with this argument. Therefore, adsorption and size exclusion were most probably two important mechanisms in the EDCs rejections by UTC60 in absence of NOM. As suggested by Nghiem $e t$ al. [8], adsorption and size exclusion were most likely the two major separation mechanisms respectively in the beginning and later stage of filtration in absence of NOM.

The significance of NOM in binding and removing organic pollutants is well documented $[2,3,20,22]$. Since EDCs can be adsorbed on NOM molecules as well as on membrane surface in presence of NOM, rejection mechanisms in such a case could be more complicated than in absence of NOM. The EDCs rejection scenario with NOM presented in this article did not have clear-cut trends even though the rejections were, in general, significantly higher than in absence of the NOM. NOM molecules are readily adsorbed on membrane surface and negatively charged functional groups in NOM dominate membrane surface charge resulting to increase in negative zeta potential [18], which most probably further decreases membrane pore sizes. Although we do not have zeta potential data for UTC- 60 in presence of the NOM in this article, it is presumed that negative zeta potential values of the membrane increased significantly with the NOM and increasing solution $\mathrm{pH}$, which resulted in higher EDCs rejections.

Since the EDCs rejections in presence of the NOM presented in this article (Figure 3) cannot be fully explained only on the basis of molecular weights of the NOM (Table 2) and their adsorption coefficient values with the EDCs (Table 3), further investigations are necessary to elucidate the complex retention mechanisms. Nevertheless, adsorption and size exclusion were presumably the major rejection mechanisms in presence of NOM. The EDCs molecules could have been retained by their adsorption on membrane surface and by size exclusion, which were similar to their rejections in absence of the NOM. However, it was most likely that the EDCs were adsorbed on NOM molecules, which were adsorbed on the membrane surface and/or retained by size exclusion mechanism since the rejections in the latter case were significantly higher.

Nghiem et al. [8] proposed that pollutant diffusion through the membrane polymer matrix, which reduces retention efficiency, could be important in the later stage of membrane filtration in addition to size exclusion. Some anomalies observed in the EDCs rejections by UTC-60 in presence of NOM (for example: higher rejections of E2 and BPA with HA than with EfOM despite the similar weights of their molecules, and almost similar rejections of E2 and NP with HA and FA although the $k_{d}$ values of HA and FA with NP were about two-fold bigger that with E2) may be attributed to the "diffusion through the membrane matrix" effect in addition to physicochemical properties of the EDCs and effects of varieties of organic matters present in the EfOM that were probably not detected in size-exclusion chromatographic analysis.

\subsection{CONCLUSIONS}

Rejections of the three EDCs by UTC-60 membrane were strongly dependent on solution pH, membrane zeta potential and presence of NOM like HA, FA, and EfOM in solutions. The EDCs rejections and membrane zeta potential increased with solution $\mathrm{pH}$ in absence of the NOM. Adsorption of the EDCs molecules on the membrane surface and their retention by size exclusion (molecular sieving) were the most likely rejection mechanisms in this case. The presence of the NOM in solutions had high significance for the EDCs rejections by UTC-60. Their presence enhanced the EDCs rejections due to dominance of negatively charged functional groups on the membrane surface that came from 
easily adsorbed NOM molecules, and possibly increased negative zeta potential of the membrane. The EDCs rejections in presence of NOM did not have specific trends possibly due to diffusion of the adsorbed NOM and EDCs molecules through the membrane matrix, and other unknown interactions among them. Adsorption of the EDCs on NOM molecules and their subsequent adsorption on membrane surface and/or their retention by size exclusion were the most likely rejection mechanisms of the EDCs by UTC-60 in presence of the NOM.

\section{REFERENCES}

[1] Ozaki, H., and H. Li. 2002. Rejection of Organic Compounds by Ultra Low Pressure Reverse Osmosis Membrane. Wat. Res. 36(1): 123-130.

[2] Braghetta, A., F. A. DiGiano, and W. P. Ball. 1997. Nanofiltration of Natural Organic Matter: $\mathrm{pH}$ and Ionic Strength Effects. J. of Env. Eng. (ASCE). 123(7): 628-641.

[3] Thanuttamavong, M., J. I. Oh, K. Yamamoto, and T. Urase. 2001. Comparison Between Rejection Characteristics of Natural Organic Matter and Inorganic Salts in Ultra Low Pressure Nanofiltration for Drinking Water Production. Wat. Sci. \& Tech.: Water Supply. 1(5-6): 77-90.

[4] Ratanatamskul, C., K. Yamamoto, T. Urase, and S. Ohgaki. 1996. Effect of Operating Conditions on Rejection of Anionic Pollutants in the Water Environment by Nanofiltration Especially in Very Low Pressure Range. Wat. Sci. \& Tech. 34(9): 149-156.

[5] Ozaki, H., N. Ikejima, S. Matsui, Y. Terashima, S. Takeda, I. Tari, and H. Li. 2002b. The Role of Membrane $\zeta$-potential in Solute Rejection by Low Pressure Reverse Osmosis. Wat. Sci. \& Tech.: Water Supply. 2(5-6): 321-328.

[6] Fujikawa, Y., T. Hamasaki, M. Sugahara, H. Ozaki, G. Prasai, T. Yano, R. Imada, Y. Tainaka, W. Nakamura, and F. Haruki. 2004. Re-evaluation and Reconstruction of Water Purification System Using Soil I: Assessment of Soil as a Sorbent of Humic Substances and Phosphate Ion. Wat. Sci. \& Tech. 50: 363-367.

[7] Gauthler, T. D., W. R. Seltz, and C. L. Grant. 1987. Effects of Structural and Compositional Variations of Dissolved Humic Materials on Pyrene $K_{o c}$ Values. Environ. Sci. Technol. 21(3): 243-248.

[8] Nghiem, L. D., I. S. Andrea, and E. Menachem. 2004. Removal of Natural Harmones by Nanofiltration Membranes: Measurement, Modeling and Mechanisms. Environ. Sci. Technol. 38: 1888-1896.

[9] Voogt, P. de, and B. van Hattum. 2003. Critical Factors in Exposure Modeling of Endocrine Active Substances. Pure and Appl. Chem. 75(11-12): 1933-1948.

[10] Charles, A. S., B. D. Phillip, M. K. Gray, T. O. Sondra, and R. H. Lynne. 1998. A Review of the Environmental Fate, Effects and Exposures of Bisphenol A. Chemosphere. 36(10): 21492173.

[11] Lipnick, R. L., C. K. Bickings, D. E. Johonson, and D.A. Eastmond. 1986. Comparison of Quantitative Structure Activity Relationship Predictions with Fish Toxicity Screening Data for 110 Phenols. ASTM Spec. Publ. 891: 153-176.

[12] Ikawa, M., S. Yoshida, and T. Yamabe. 1975. The Effect of pH on Reverse Osmosis Membrane Properties. J. of Chem. Soc, of Japan. 10: 1713-1716.

[13] Childress, A. E., and E. Menachem. 2000. Relating Nanofiltration Membrane Performance to Mmembrane Charge (electrokinetic) Characteristics. Environ. Sci. Technol. 34: 3710-3716.

[14] Borretzen, P., and B. Salbu. 2005. Geochemical Models for Sediment-seawater Interactions. Report. Institute for Chemistry and Biotechnology. Agricultural University of Norway. 
[15] Asada, T., K. Oikawa, K. Kawata, S. Ishihara, T. lyobe, and A. Yamada. 2004. Study of Removal Eeffect of Bisphenol A and $\beta$-Estradiol by Porous Carbon. J. of Health Science. 50(6): 588593.

[16] Yoon, Y., P. Westerhoff, J. Yoon, and S. A. Snyder. 2004. Removal of 17b-Estradiol and Fluoranthene by Nanofiltration and Ultrafiltration. J. of Env. Eng. (ASCE). 130(12): 14601467.

[17] Agenson, K. O. 2004. Controlling Hazardous Chemical Compounds by Nanofiltration/Reverse Osmosis in Water and Wastewater Treatment. Ph.D. Thesis. Department of Civil Engineering, Tokyo Institute of Technology. Japan.

[18] Childress, A. E., and M. Elimelech. 1996. Effect of Solution Chemistry on the Surface Charge of Polymeric Reverse Osmosis and Nanofiltration Membranes. J. of Membrane Science. 119: 253-268.

[19] Yamada, E., K. Doi, K. Okano, and Y. Fuse. 2000. Simultaneous Determination of the Concentration and Molecular Weights of Humic Substances in Environmental Water by Gel Chromatography with a Fluorescence Detector. Analytical Sciences. 16: 125-129.

[20] Koopal, L. K., W. H. Riemsdijk, and D. G. Kinniburgh. 2001. Humic Matter and Contaminants: Aspects and Modeling Metal Ion Binding. Pure and Appl. Chem. 73(12): 2005-2016.

[21] Wershaw, R. L. 1989. Application of a Membrane Model to the Sorptive Interactions of Humic Substances. Environ. Health Persp. 83: 191-203.

[22] Won-Young, A., Y. Seong-Keun, S. Byung-Yong, K. Geon Tae, A. Hyowon, L. Dongjoo, L. Sangyoup, K. Boksoon, and C. Jaeweon. 2004. Experimental Evaluations of a Pilot Nanofiltration System with Respect to NOM and BOM Removals and Stable Permeability with Appropriate Pre-treatments: A Case Study in Korea.J. of Water Supply: Res. and Tech.-Aqua. 53(3): 169181. 